\title{
INTERAÇÃO DE CRIANÇAS COM MULTIDEFICIÊNCIA
}

\author{
Filipa Santos ${ }^{1}$ and Mónica Silveira-Maia ${ }^{2}$ \\ ${ }^{1}$ Agrupamento de Escolas de Matosinhos; ${ }^{2}$ Escola Superior de Educação do Instituto Politécnico do Porto (ESE-IPP) \\ Palavras-chave: Interação pais-criança, Interação irmão-criança, Multideficiência.
}

\begin{abstract}
A determinação de padrões de interação de crianças com necessidades complexas de comunicação decorrentes de quadros de multideficiência, tem vindo a ocupar importância central no planeamento de intervenções orientadas para a participação. Tomando o contexto familiar como principal cenário instigador dos processos de funcionalidade - definidos por situações de mútua participação e entendimento -, neste estudo partimos da percetiva dos pais e irmãos de crianças com multideficiência para a descrição das díades interacionais estabelecidas neste contexto e para a sistematização de fatores ambientais associados a interações bem-sucedidas.
\end{abstract}

Foram entrevistadas famílias de sete crianças com multideficiência, com recurso a um guião centrado na descrição das formas, conteúdos e momentos de interação, bem como, dos fatores contextuais relacionados com as interações bem-sucedidas. Usaram-se técnicas de análise de conteúdo indutivas e dedutivas através do mapeamento das unidades de significado à Classificação Internacional de Funcionalidade, Incapacidade e Saúde (CIF-CJ). Os resultados levam a uma reflexão sobre fatores que estão na base das interações bem-sucedidas, especificamente ao nível do papel assumido pelos pais e irmãos no entendimento de movimentos corporais/ gestos naturais, expressões faciais e vocalizações produzidas pela criança com intenção de expressar sentimentos, iniciar interações e fazer pedidos. A partir da análise das respostas dos entrevistados, identificou-se a compreensão mútua em situações de brincar como base do discurso referente à díades irmão-criança, por oposição às situações de estimulação do desenvolvimento geralmente associadas às situações de interação pais-criança, cujos conteúdos se orientam para a antecipação/descrição de acontecimentos. Estratégias facilitadoras usadas no contexto familiar - desde a repetição à estruturação e consistência de rotinas - são sistematizadas tendo por base a identificação de relações reciprocas entre atividades e participação, fatores ambientais e funções do corpo.

\section{INTRODUÇÃ̃O}

A comunicação enquanto indicador operacional da interação social e, por consequência, da participação e inclusão das crianças e jovens com multideficiência, tem assumido protagonismo, sendo considerada área prioritária na exploração de linhas de intervenção dirigidas a esta população (Amaral, Saramago, Gonçalves, et al., 2004; Granlund and Olsson, 1999; Wilder and Granlund, 2003). De facto, além da geral definição que sublinha a presença de incapacidades múltiplas, os perfis de funcionalidade inscritos em quadros de multideficiência descrevem comummente a presença de necessidades complexas de comunicação referentes a situações cujas deficiências motoras, linguísticas, cognitivas e/ou sensoriais impedem o desenvolvimento da fala, gerando restrições significativas na interação e comunicação com os outros. Inscrevendo-se numa comunicação pré-simbólica (e.g., vocalizações, expressões faciais, movimentos corporais, gestos naturais e olhar), os comportamentos comunicativos destas crianças/jovens são muitas vezes descritos como difíceis de interpretar, colocando desafios vários no estabelecimento e manutenção das interações sociais (Amaral, Saramago, Gonçalves, et al., 2004; Nunes and Amaral, 2008).

O enfoque na comunicação enquanto objetivo de intervenção tem-se, no entanto, visto destituído de uma análise contextual capaz de o tornar num efetivo mediador da interação e participação, considerando mecanismos de suporte à criança e à família que estejam embebidos nas suas rotinas e nos seus contextos naturais de vida. O entendimento das restrições experienciadas por crianças com multideficiência no relacionamento e interações sociais - considerando os seus contextos de participação continua ainda a ser um domínio de conhecimento a descoberto (Wilder, Axelsson and Granlund, 2004).

Nesta linha de pensamento, vários estudos têm vindo a explorar a perceção dos cuidadores sobre a interação estabelecida, esboçando linhas orientadoras para o delineamento de intervenções focadas em indicadores de participação e estratégias ambientais facilitadoras (e.g., Ibragimova, Lillvist, Pless, et al., 2007; Wilder, Axelsson, and Granlund, 2004; Wilder and Granlund, 2003). 
Este processo de identificação de padrões que possam conduzir à tipificação de necessidades de suporte, tem sido acompanhado da preocupação de devolver resultados que se possam enquadrar sobre uma terminologia universal capaz de se fazer disseminar entre a investigação e as práticas. De facto, esta mesma tendência tem sido verificada no domínio específico deste estudo, onde diversos autores (Ibragimova, Lillvist, Pless, et al., 2007; Simeonsson, Björck-Akessön and Lollar, 2012; Wilder, Axelsson, and Granlund, 2004) têm vindo a dedicar-se à categorização da informação relativa às incapacidades de comunicação de crianças e jovens, com referência à Classificação Internacional de Funcionalidade, Incapacidade e Saúde (CIF) de modo a apoiar os processos de tomada de decisão no planeamento da intervenção.

Tomando como ponto de partida estudos prévios - onde o enfoque das situações de interação é baseado na perspetiva dos pais (e.g., Ibragimova, Lillvist, Pless, et al., 2007; Wilder, Axelsson, and Granlund, 2004; Wilder and Granlund, 2003) -, este estudo alarga o espectro de análise também aos irmãos de crianças/jovens com necessidades complexas de comunicação, pretendendo caracterizar as interações estabelecidas e identificar elementos da funcionalidade e do contexto que estejam na base de situações de interação bem-sucedidas.

Deste modo, este estudo tem como objetivo explorar a perspetiva dos pais e irmãos de crianças/jovens com necessidades complexas de comunicação acerca das díades interacionais pais-criança e irmão-criança, procurando responder às seguintes questões de investigação: $(i)$ De que modo os pais e irmãos de crianças com necessidades complexas de comunicação descrevem a interação estabelecida entre eles? (ii) Que fatores da funcionalidade e do contexto definem, segundo a perspetiva dos pais e irmãos, as interações pais-criança e irmão-criança bemsucedidas?.

\section{MÉTODO}

\section{Participantes}

Os participantes deste estudo referem-se a sete famílias de crianças/jovens com necessidades complexas de comunicação. Socorrendo-nos de um processo de amostragem por conveniência, as famílias foram recrutadas através das Unidades de Apoio Especializado para a Educação a Alunos com Multideficiência e Surdocegueira Congénita (UAEEAMSC) próximas do círculo de intervenção das autoras deste estudo, contemplando cinco agrupamentos de escolas localizados no distrito de Aveiro, Portugal.

Os participantes recrutados dizem respeito a famílias de crianças/jovens - com idades compreendidas entre os seis e os quinze anos -, cujos diagnósticos e caracterizações da funcionalidade remetiam para um quadro de multideficiência. Os diagnósticos clínicos enquadram situações muito diversas desde síndrome dismórfico $(n=1)$; a micro- cefalia $(n=1)$; a trissomia $18(n=1)$; a atraso neuropsicomotor $(n=1)$; a citopatia mitocondrial $(n=1)$; e a casos sem diagnóstico definido $(n=2)$.

As crianças/jovens - cinco do género feminino e duas do género masculino - frequentavam o pré-escolar $(n=1) ; 1^{\circ}$ ano de escolaridade $(n=3) ; 2^{\circ}$ ano $(n=1)$ e $4^{\circ}$ ano $(n=2)$.

Alguns dos fatores considerados como critérios de inclusão foram: (i) o facto das crianças/jovens das famílias elegidas residirem com os pais e irmãos; bem como (ii) apresentarem necessidades complexas de comunicação. Tomando como referência a definição de Light and Drager (2007), assumimos que o conceito de necessidades complexas de comunicação se refere a situações cujas deficiências motoras, linguísticas, cognitivas e/ou sensoriais impedem o desenvolvimento da fala, gerando significativas restrições no acesso ao ambiente e na interação e comunicação com os outros. A seleção das famílias participantes fez-se a partir da congruência entre esta definição e a caracterização do desempenho das crianças/ jovens nos domínios da comunicação e interação - tendo por base a opinião/ conhecimento das professoras e/ou profissionais que as acompanhavam.

Em cada família foi solicitada a participação de um dos pais e de um irmão. Participaram e foram entrevistados individualmente seis mães, um pai e sete irmãos. Os irmãos entrevistados apresentavam idades compreendidas entre os seis e os dezasseis anos; e os pais entre os 36 e os 43 anos.

\section{Instrumentos de recolha de dados}

Em ordem a obter um retrato da interação estabelecida nas díades entre pais/irmãos e crianças com necessidades complexas de comunicação, socorremo-nos de uma entrevista semi-estruturada - dirigida aos pais e adaptada aos irmãos.

O guião de entrevista foi organizado em torno de quatro grandes tópicos: (1) formas e situações de comunicação e interação; (2) objetivos e conteúdos de comunicação estabelecidos; (3) identificação de situações bem-sucedidas de interação; (4) identificação de facilitadores no processo de interação e comunicação. O guião foi sujeito a uma análise crítica por um painel de três experts, composto por terapeutas da fala, com mais de cinco anos de experiencia profissional na área da multideficiência. Este painel avaliou a clareza e pertinência dos itens da entrevista e com base no feedback recebido procedeu-se aos ajustamentos necessários.

\section{Análise de dados}

O escrutínio das respostas dos participantes fez-se com recurso a técnicas de análise de conteúdo. A determinação dos temas de análise obedeceu a um sistema categorização de natureza dedutiva - baseado nos tópicos do guião da entrevista - e indutiva (decorridas da tendência/ padrões de discurso dos participantes). As categorias 
foram determinadas, segundo dois momentos de análise. Um primeiro, em que se pretendia obter um retrato compreensivo da caracterização dos pais e irmãos sobre as interações estabelecidas, e onde o sistema de categorização teve natureza indutiva. Num segundo momento, para uma identificação sistemática de elementos da funcionalidade e do contexto relacionados com os processos de interação descritos, a análise de conteúdo socorreu-se de uma categorização dedutiva, mediada por um mapeamento dos conteúdos na CIF-CJ. Para o efeito, as unidades de significado foram ligadas aos códigos da CIF-CJ, tomando por referência as regras de codificação enunciadas por Cieza, Geyh, Chatterji, et al. (2005). A análise de conteúdo foi levada a cabo por uma das autoras do estudo, acompanhada pela codificação independente por um par - tendo sido obtidas medidas de concordância situadas acima dos 90\%. Neste processo, os pontos de discordância foram discutidos até que uma codificação consensual fosse alcançada.

\section{RESULTADOS}

Formas comunicativas utilizadas pela criança

As formas comunicativas utilizadas pela criança foi o tema mais abordado na descrição das díades interacionais pais-criança e irmão-criança. Os movimentos corporais, as vocalizações e as expressões faciais parecem representar as principais formas de comunicação descritas quer pelos pais quer pelos irmãos (Tabela 1).

Funções comunicativas utilizadas criança

As funções comunicativas usadas pela criança mais vezes enumeradas pelos pais e irmãos, foram (Tabela 1): iniciar a interação e expressar sentimentos: "Se estiver ao pé de mim está sempre a dizer Olá”. A função fazer pedidos encontrou também destaque no discurso dos pais: "Se forem coisas que ela quer, como se for para pedir comida, ela vem muitas vezes ter connosco e aponta o que quer".

Conteúdos de comunicação

Na díade de interação pais-criança, o principal conteúdo de comunicação (Tabela 1) foi alusivo a tarefas que objetivam estimular o desenvolvimento da criança: "Eu às vezes pego na roupa das bonecas e tiro-a e depois começo: "onde está o casaco?" Vejo se ela olha". Já no que se refere à díade irmão-criança, o brincar parece ser o conteúdo de comunicação mais importante: "Brincamos aos legos".

Em três descrições da díade interacional pais-criança, surgiu também frequentemente conteúdos de comunicação

Tabela 1: Número de unidades de significado (e de casos) identificadas nas respetivas categorias:

\begin{tabular}{|c|c|c|c|}
\hline \multirow[b]{2}{*}{ Temas } & \multirow[b]{2}{*}{ Categorias } & \multirow{2}{*}{$\begin{array}{l}\text { Díade Pais-Criança } \\
\mathrm{N}^{\circ} \text { U.S. ( } \mathrm{N}^{\circ} \text { Casos) }\end{array}$} & \multirow{2}{*}{$\begin{array}{c}\text { Díade Irmão-Criança } \\
\mathrm{N}^{\circ} \text { U.S. }\left(\mathrm{N}^{\circ} \text { Casos) }\right.\end{array}$} \\
\hline & & & \\
\hline Formas comunicativas & Movimentos Corporais & $25(6)$ & $6(7)$ \\
\hline \multirow[t]{4}{*}{ utilizadas pela criança } & Vocalizações & $21(6)$ & $5(2)$ \\
\hline & Expressões Faciais & $13(5)$ & $3(3)$ \\
\hline & Olhar & $4(4)$ & \\
\hline & Palavras & $4(3)$ & $4(2)$ \\
\hline \multirow{5}{*}{$\begin{array}{l}\text { Funções comunicativas } \\
\text { utilizadas pela criança }\end{array}$} & Expressar sentimentos & $16(4)$ & $2(1)$ \\
\hline & Iniciar interação & $9(6)$ & $3(2)$ \\
\hline & Responder à interação & $4(3)$ & $1(1)$ \\
\hline & Fazer pedidos & $12(6)$ & $2(1)$ \\
\hline & Solicitar/Dar informações & $5(2)$ & \\
\hline \multirow[t]{7}{*}{ Conteúdos de comunicação } & Brincar & $8(5)$ & $9(6)$ \\
\hline & Estimular o desenvolvimento & $17(6)$ & $6(2)$ \\
\hline & Antecipar /Descrever acontecimentos & $17(3)$ & \\
\hline & Repreender & $8(4)$ & $1(1)$ \\
\hline & Demonstrar afeto & $2(2)$ & $1(1)$ \\
\hline & Proporcionar Bem-estar & $2(2)$ & $3(1)$ \\
\hline & Obter informação & & $2(1)$ \\
\hline \multirow{6}{*}{$\begin{array}{l}\text { Papéis desempenhados } \\
\text { pelos pais e irmãos }\end{array}$} & Compreender a criança & $3(2)$ & $2(2)$ \\
\hline & Iniciar a Interação & $8(5)$ & $4(4)$ \\
\hline & Equidade no tratamento dos irmãos & $3(2)$ & \\
\hline & União/Companheirismo & & $1(1)$ \\
\hline & Auxilio nos cuidados e tarefas diárias & & $1(1)$ \\
\hline & Defesa e Proteção & & $2(1)$ \\
\hline
\end{tabular}

U.S. = Unidades de significado 
referentes à descrição de acontecimentos que estão a decorrer naquele momento ou à antecipação dos acontecimentos seguintes: "Eu digo o que vou fazer com ele. Entendendo ou não, eu faço com ele".

\section{Papéis desempenhados pelos pais e irmãos}

O papel dos pais está relacionado com a compreensão da comunicação da criança e/ou do seu estado emocional, com a iniciação da interação com esta, sendo também salientada uma dimensão de equidade no tratamento dos irmãos (Tabela 1), independentemente das duas diferenças: "Eles foram crescendo e eu tentei dar sempre o mesmo aos dois. Se dou um beijo a um dou a outro". O papel dos irmãos foi também dimensionado à compreensão da criança e à iniciação da interação. "A categoria de uniào/ companheirismo viu-se também refletida nas respostas dos entrevistados, como é exemplo a frase: Não a deixo sozinha, estou sempre ao lado dela"

\section{Códigos chave no retrato das interações pais-criança e} irmãos-criança

A descrição das interações pais-criança e irmãos enquadrou-se preferencialmente em indicadores relativos ao componente das Atividades e Participação (67.8\% das referências totais), assumindo maior relevância os domínios da comunicação (d3, - 58.9\% das referências totais às Atividades e Participação) e das interações e relacionamentos interpessoais (d7 $-12.8 \%$ das referências). No domínio da comunicação, a produção de mensagens usando linguagem corporal (d3350) foi o indicador mais referido (34.6\% das referências ao domínio da comunicação). Já no domínio das interações, foram os indicadores de iniciação de interações sociais (d71040) e a regulação do comportamento nas interações (d7202). O segundo componente mais abordado pelos pais e irmãos foi o referente aos Fatores Ambientais - 25.4\% das referências totais. $\mathrm{O}$ apoio e relacionamentos da família próxima (e310 - 59.8\% do total de referências aos Fatores Ambientais) surgiu com maior destaque, servindo para explicar estratégias de apoio usadas (e.g., falar com a criança; explicar-lhe o que está a acontecer; tentar percebê-la; estar recetiva às suas iniciativas e responder-lhe; acarinhá-la). Assumiu também destaque no discurso dos pais os produtos e tecnologias de apoio para a comunicação (e1251), enquadrando menções a estratégias usadas para facilitar a comunicação com a criança (e.g., perguntas fechadas, dupla escolha, gestos, repetição). Por fim, no que respeita à componente das Funções e Estruturas do Corpo, as referências centraram-se nas funções emocionais (b152 - 71.4\% do total de referências às Funções do Corpo).

\section{DISCUSSÃO}

$\mathrm{Na}$ descrição das interações estabelecidas, os pais e irmãos, indicam os movimentos corporais/ gestos naturais, as vocalizações e as expressões faciais, como principais formas de comunicação usadas pela criança/jovem. Quanto às funções comunicativas, a expressão de sentimentos (e.g., agrado, satisfação e alegria face a situações ou atividades), a realização de pedidos para satisfazer necessidades ou atingir objetivos (e.g.,. pedir alimentos ou algum objeto) e a iniciação de interações são na perspetiva dos pais e irmãos as principais intencionalidades inerentes aos atos comunicativos da criança.

Estando um dos elementos centrais a definir o papel dos pais e irmãos colocado ao nível da compreensão, o entendimento de movimentos corporais/ gestos naturais, expressões faciais e vocalizações com a finalidade de expressar sentimentos, iniciar interações e fazer pedidos, parece ser um elemento chave das díades interacionais pais-criança e irmão-criança. Este aspeto encontra reflexo no estudo de Wilder and Granlund (2003), onde sublinha o facto da interação de crianças com multideficiência exigir dos pais maior sensibilidade na interpretação das suas expressões, procurando as suas iniciativas e respostas. Para além do papel de compreensão, é também destacada a iniciação de interações e a união/companheirismo - no caso da díade irmão-criança - como papéis assumidos pelos entrevistados. Tal encontra reflexo na descrição dos conteúdos da comunicação que revelam o brincar como situação preferencial de interação. Já na descrição da díade pais-criança encontra-se no discurso dos pais maior menção a situações de instigação do desenvolvimento. A saliência da intenção de estimulação do desenvolvimento na descrição das situações de interação - em detrimento de situações que apelem mais a momentos de descontração/ prazer inseridos no quotidiano da família (e.g., demonstrar afeto, brincar) - parece colocar em evidência a necessidade que tem vindo a ser destacada na literatura de serem implementadas abordagens de intervenção primariamente conduzidas pelas necessidades e rotinas da família (e.g., Dunst, 2000).

A partir da análise efetuada à descrição da interação destas crianças, através do mapeamento dos conteúdos na CIF-CJ, destacamos os códigos situados no componente de Atividade e Participação, no domínio da comunicação (d3) e o código referente ao envolvimento no jogo (d880), assim como o código relativo ao apoio e relacionamento da família próxima (e310), do componente dos Fatores Ambientais, como principais elementos caracterizadores das interações entre pais-criança e irmão-criança.

\section{Conflicts of interest}

The authors report no declarations of interest.

Address for correspondence

Filipa Santos,

Av. Beira-Mar 1601-B $2^{\circ}$ Esq. 4400-382

Canidelo - Vila Nova de Gaia

PORTUGAL

Email: filipalgsantos@ hotmail.com 


\section{Referências bibliográficas}

Amaral, I., Saramago, A., Gonçalves, A., Nunes, C. \& Duarte, F. (2004). Avaliação e Intervenção em Multideficiência. Lisboa: DGIDC, Ministério da Educação.

Cieza, A., Geyh, S., Chatterji, S., Kostanjsek, N., Üstün, B. \& Stucki, G. (2005). ICF linking rules: an update based on lessons learned. Journal of Rehabilitation Medicine, 37, 212-218.

Dunst, C. (2000). Revisiting "Rethinking Early Intervention". Topics in Early Childhood Special Education, 20(2), 95-104.

Granlund, M. \& Olsson, C. (1999). fficacy of communication intervention for presymbolic communicators. Augmentative and Alternative Communication, 15, 25-37.

Ibragimova, N., Lillvist, A., Pless, M. \& Granlund, M. (2007). The utility of ICF for describing interaction in non-speaking children with disabilities - caregiver ratings and perceptions. Disability and Rehabilitation, 29(22), 1689-1700.

Light, J. \& Drager, K. (2007). AAC Technologies for young children with complex communication needs:
State of the science and future directions.

Augmentative and Alternative Communication, 23(1), 204-216.

Nunes, C. \& Amaral, I. (2008). Educação, Multideficiência e Ensino Regular: Um processo de mudança de atitude. Revista Diversidades, 20, 4-9.

Organização Mundial de Saúde (2007). International Classification of Functioning, Disability and Health, for Children and Youth (ICF - CY). Genebra:

Organização Mundial de Saúde.

Simeonsson, R., Björck-Akessön, E. \& Lollar, D. (2012). Communication, Disability, and the ICF-CY.

Augmentative and Alternative Communication, 28(1), 3-10.

Wilder, J., Axelsson, C. \& Granlund, M. (2004). Parentchild interaction: a comparison of parents' perceptions in three groups. Disability and Rehabilitation, 26 (21, 26(21/22), 1313-1322.

Wilder, J. \& Granlund, M. (2003). Behaviour style and interaction between seven children with multiple disabilities and their caregivers. Child: Care, Health \& Development, 29(6), 559-567. 